\title{
Tanning, Spinning, and Gathering Together: Intergenerational Indigenous Learning in Textile Arts
}

\author{
Cindy Hanson, Heather Fox Griffith
}

\begin{abstract}
Intergenerational Learning in Indigenous Textile Communities of Practice was an interdisciplinary arts- and community-based study that inquired into the intergenerational practices of beading and weaving in two Indigenous contexts - one in Southern Chile and the other in Northern Saskatchewan, Canada. The research process involved building relational networks, developing decolonizing methodologies, and working with collaborators, elders, community coordinators, and members of Indigenous textile communities of practice. The research methods, which are a focus of this article, included the use of artifacts to draw out memories and stories of intergenerational learning and to engage the communities in deciding how to share the knowledge generated. Both the data gathering methods and the knowledge mobilization led to arts-based outcomes. The study specifically inquired into how learning is structured and passed on to subsequent generations within communities of practice and the findings provide insights into the way this knowledge is transferred and/or disrupted. Critical reflection on the process highlighted some of the challenges that arose - both with the academic researcher and the community and inside the community.
\end{abstract}

KEYWORDS intergenerational learning; indigenous research methodologies; arts-based research; material culture; community of practice

\begin{abstract}
"Epistemology is the understanding of knowledge that one adopts and the philosophy with which research is approached. This issue cannot be disentangled from history or from the social position one holds within society as a result of that history" (Cochran et al., 2008, p. 24)
\end{abstract}

The concept of space is an important one in Indigenous arts. Mary Pratt (1991) describes Indigenous arts as taking place in the "social spaces where cultures meet, clash, and grapple with each other, often in contexts of highly asymmetrical relations of power, such as colonialism, slavery, or their aftermaths as they are lived out in many parts of the world today" (p. 34). Pratt (1991) refers to this space as "the contact zone" (p. 34). Similarly, Celia Haig-Brown (2008) argues that "When we really begin to take Indigenous thought seriously in our theory and in our practice, we move to inhabit border worlds" (p. 14). The study Intergenerational Learning in Indigenous Textile Communities of Practice demonstrated an example of research in this space. 
Efforts to understand and build meaning in this borderland included attention to critical Indigenous methodologies (Denzin, Lincoln, \& Smith, 2008). In practice, this meant making the kind of postcolonial commitment suggested by Kajner (2015), which is built on disrupting colonial patterns through attention to reciprocity and equity. Among other things, this postcolonial commitment included considerable efforts toward building relational networks

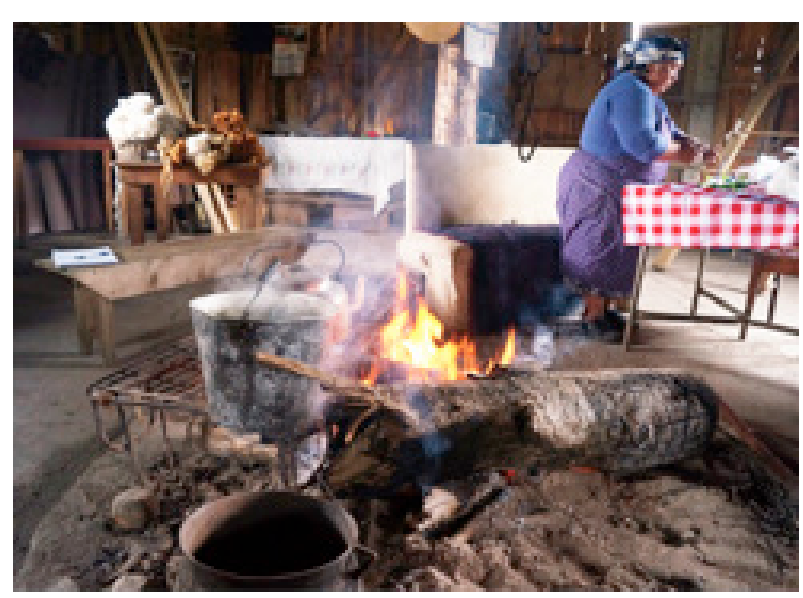

Figure 1: The Ruka for the Petrufkin focus group. with Indigenous communities, developing ethical and appropriate frameworks, and drawing upon postcolonial methodologies (Chilisa, 2012; Tuhiwai Smith, 2012). Artifacts were used to draw out memories and stories of intergenerational learning evident in the traditional 'material culture $^{11}$ of beading, weaving, textile and garment making. These methods are described in this article.

According to McNiff (2004), arts-based research can be characterized as the systematic study of artistic processes or artistic expressions to gain a deeper understanding of the experiences of the researcher and study participants. Although the study on intergenerational learning was not originally framed as an arts-based inquiry, both the data gathering methods and the process of research mobilization led to arts-based learning and outcomes. Arts-based research that is focused on artifacts created by artisans who are knowledgeable and skilled in traditional 'material culture'2 requires a deep understanding of how quickly the forms of these artifacts can change and devolve when an experienced teacher is absent, when materials are changed or become unavailable, or when the learning is disrupted (Markowitz, 1994; Tehrani \& Riede, 2008).

During the focus groups and interviews, the weavers and beaders had opportunities to share stories, ask each other questions, and compare their work and experiences. These exchanges

\footnotetext{
1 According to Tehrani \& Riede (2008), a material culture in the context of Indigenous artifacts, exists when traditional knowledge and skills are passed down from generation to generation, whereby "recognizably coherent lineages of tool-making and craft production can be traced through continuities among artifacts produced hundreds, even thousands of years apart" (p. 317).

2 Distinctions between objects are typically framed as arts or crafts, with crafts perceived as more functional and art as more aesthetic. The distinctions are contested. The authenticity and intention of an individual artist is expected to be evident in an art piece according to Western distinctions, whereas the aesthetic of Indigenous crafted objects may reflect community values, attention to the materials utilized in the creation of the work and the natural world from which they originate, as well as the authentic intention of the artist in its creation. The distinctive valuation of handcrafted arts and crafts originates as a European concept, primarily defined in ways that have historically served the interests of male artists. These distinctions have typically undermined or negated the value of objects created by women, individually and collectively, and left unrecognized the traditional knowledge and skill expressed in their making (Markowitz, 1994; Tehrani \& Riede, 2008).
} 
shaped deeper understandings of their artistic creations, for both the weavers and beaders and the researcher. In a broad sense, this model allowed the research to include storytelling and artistic processes involved in the making of traditional arts and crafts as a means to better understand and to rethink the interactions between the members of the communities of practice and their work.

Framing the study around the concept of a community of practice $(\mathrm{CoP})$, that is, a community involved in textile practices, was a way to explore knowledge transmission, sharing, and change over generations of learners. A CoP is "formed by people who engage in a process of collective learning in a shared domain" (Wenger, 2006, p. 1), and it is a situated and local site of learning where people are linked by a sense of belonging, meaning, identity and practice. Thus, the CoP constitutes a valuable site for research on informal learning because of its stability (Lave \& Wenger, 1991). One of the goals of the study then was to offer a particular example of how an Indigenous CoP supported intergenerational relationships, situated ontologies, and provided a forum for understanding and reacting to an increasingly globalized economic system. Snyder and Wenger (2004) argue a CoP has three basic characteristics which they described as domain, community, and practice. The domain is the shared interest of the group, in this case, weaving or beading, which the members feel so passionately about it becomes part of their identity. The community describes the engagement and relationships among the members so that they can learn with intentionality from each other (Wenger, 2006). The practice is the actions or shared repertoire of the group, including the tools, methods, stories, or models used for learning (Wenger, 2006).

The study explored informal ${ }^{3}$ adult learning and textile production in two Indigenous contexts, one in southern Chile and the other in morthern Saskatchewan, Canada. The research sites were chosen based on the researcher's experiences working with Indigenous peoples in Canada (Saskatchewan) and Chile and as an ally in struggles for social justice. The beaders in Saskatchewan identified as coming from Metis, Dene, and Cree ancestry. The weavers from Chile identified themselves as Mapuche.

The inquiry operated within an interdisciplinary space that was shaped by ideas borrowed from Indigenous studies, social learning, adult education, art history, and anthropology. In addition to Wenger's conceptualization of CoPs, the study drew heavily upon poststructural understandings and critical Indigenous methodologies. This framework was intended to assist the researcher to be self-critical, reflexive, and aware of taken-for-granted knowledge that could emerge from pre-conceived ideas and well-established academic practices. Poststructuralist notions and Indigenous methodologies helped the researcher question the privileging of academic discourses in determining the legitimacy of other forms of knowledge, including knowledge from the study's participants. A fundamental principle of poststructuralist thought is to avoid the assumption of self-transparency. This is considered essential for a truly "legitimate" research practice, for as Peters and Burbles (2004) note, the concept of

\footnotetext{
3 Informal learning is defined by Coombs in Merriam, Cafferella and Baumgartner (2007) as learning that takes place daily in our relationships and encounters inside the home and in public places. It is usually not planned like non-formal learning that usually is delivered in workshops or a structured encounter.
} 
"self" as a single, coherent entity is a fictional construct. According to this poststructuralist outlook, researchers and participants might have different ideas about knowledge and identity, shaped by language, culture, spiritual beliefs and traditions, collective history, gender, class, and family (Sinclair, 2014), but studies usually ignore such underlying issues and present one "coherent" and privileged story. With this in mind, the goal of this study was to create a multi-faceted interpretation of the research work and what we thought we had learned from both the storied experiences shared by the study participants and our shared experiences. This knowing also challenged us to avoid unnecessary bias and broad generalizations. Finally, in keeping with arts-based research and Indigenous methodologies (Wilson 2008) and to illustrate how reflexivity was built into the study, the researcher (Cindy Hanson) frequently inserts her personal perspectives using first person narration, which helps move the discussion beyond academic borders.

\section{Engagement in Indigenous Research Methodologies}

The research was positioned as an engagement in methodologies that weave ethical approaches, reflexivity, a critique of a researcher's social subjectivities, and Indigenous research worldviews within cross-cultural research. As Tuhiwai-Smith (1999) asserts, contemporary research involving Indigenous peoples and communities must address the "relationship between knowledge and power, between research and emancipation, and between lived reality and imposed ideals about the other" (p. 165). Thus, it is necessary that research methodologies engage with decolonizing processes that seek to unhinge power relations and provide an ethical, culturally based foundation for practice (Ermine, 2000). For example, the translation for Indigenous languages, the participation of elders, the location for meetings, as well as the time built into the data collection process for eating together and building informal relationships were considered valuable in the data-gathering process.

Indigenous scholars frequently write about the importance of relationship-building and relationality (Wilson, 2008; Kovach, 2009). Shawn Wilson (2008), for example, asserts that for Indigenous people "a relational way of being [is] at the heart" (p. 80) of the practice. He describes it as collective, community-centered, and built upon interconnections between and among humans and the land. The development of relational networks did not start with the study. They started with earlier life experiences. For example, in 19934, I received a Canadian International Development Award (CIDA) to work alongside Mapuche women at Casa de la Mujer Mapuche. This organization worked in health and education, but most significantly, it worked with approximately 130 women in 12 Mapuche communities, assisting them with improving and marketing their woven textiles through the organization's storefront. While Casa de la Mujer Mapuche no longer exists, most of the people involved are still situated around Temuco. Around the same time, I was also building relationships with Indigenous youth and teaching Native Studies in Canada. Additionally, I coordinated an elders' program at a community college and assisted with course development for Dumont Technical

\footnotetext{
4 As iterated earlier, the researcher, Cindy Hanson, inserts personal reflections to illustrate connections to this work that
} extend beyond academic boundaries.

Engaged Scholar Journal: Community-Engaged Research, Teaching and Learning 
Training Program, a Metis training institute. I was then, and remain now, an ally of Indigenous struggles for justice. These relationships planted the seeds for this inquiry.

The relational networks in the study involved iterative and culturally-explicit work with Indigenous academic collaborators, elders, community coordinators, and CoPs. For example, relational networks in families and communities became the trails through which study participants were recruited. While recruitment for the study was not specific to women, only women volunteered to participate. Altogether, 37 Indigenous women in the two countries were involved as study participants. The community coordinators assisted in finding appropriate places to meet, in getting the study participants together, and in providing translations as necessary. Together, the collaborators and study participants developed several study questions: How is learning structured and passed on to subsequent generations within the CoP? Are there ways that intergenerational learning can be enhanced or sustained in the community, and how would the CoP benefit from this? How are identities (particularly cultural and gendered) of members of the CoP embedded in the practices of weaving or beading? In what ways, if any, might the community wish to mobilize and disseminate knowledge about the results of this study to a wider community? Being mindful of Indigenous methodologies, the decisions around how the knowledge would be shared beyond

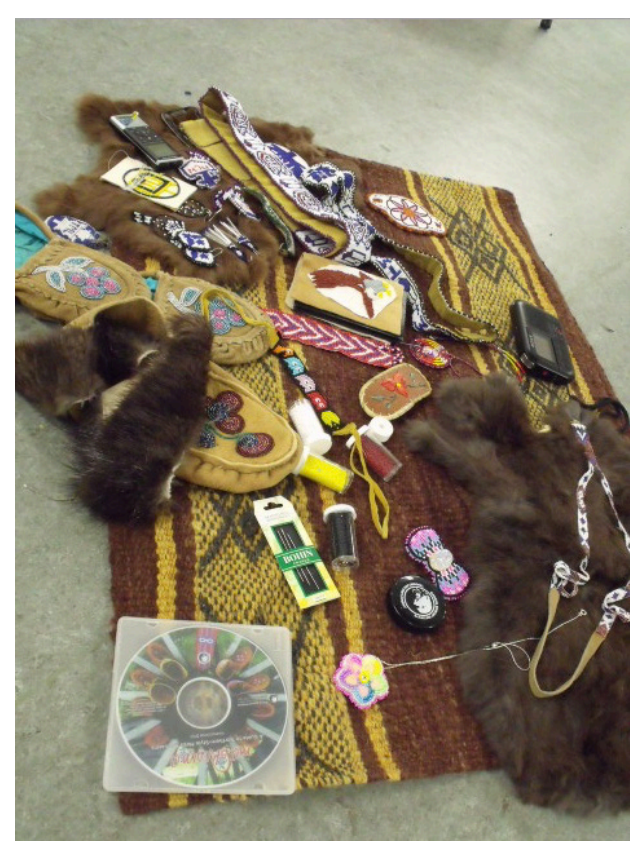

Figure 2: Gathering items for story circle focus group. academic communities involved the participation of the members of the CoPs themselves. Although the questions, like the study itself, were never originally planned as arts-based, both the subject of the study and then the methods used for gathering data changed the inquiry into one that can be described as arts-based.

\section{Arts-Based Methods}

Historically, Western research methodologies and Eurocentric ideologies have exploited Indigenous communities and knowledges (Ermine: 2000; Tuhiwai Smith, 1999). Today, Indigenous scholars argue instead for processes that are holistic and mutualistic (Battiste \& Henderson, 2000), community-driven, and guided by the elders (dé Ishtar, 2005), with the researcher locating his or her personal and social position as part of a decolonizing practice. The choice of research methods was, therefore, critical in this study. The study used mixed methods, including interviews, two story-circle focus groups, and symbol-based learning, inspired by Indigenous research methodologies. The study drew upon the work of Lavallée 
(2009) who used sharing circles and Anishnaabe symbol-based reflection as an arts-based method that emphasized story-telling and community engagement. The symbol-based learning and story-circle focus groups emphasized oral traditions and learning based on senses, including the visual, aural, and tactile (Bourdieu, 1991; dé Ishtar, 2005). The study also drew upon Pierre Bourdieu's theoretical work, which explored how knowledge can be expressed and conveyed through postures and gestures, which articulate deeper emotional aspects of the participants' memories (dé Ishtar: 2005). The use of symbols in the circle created opportunities for the participants to draw upon their memories and deeper emotions associated with them.

The data gathering methods used in this study could be described as a way to evoke blood memory or narrative memory, which are teachings and cultural practices, including rituals and ceremonies, that extended kinship pass from generation to generation (Allen, 1999; Henderson, 2000). According to Lavallée's (2009) doctoral study, knowledge can be transferred via spiritual means such as dreams or visions and "it is believed that thoughts, beliefs, and actions are conveyed from one's ancestors through the blood" (p. 22). The stories are, thus, personal and shared, individual and collective, and they give voice to experience. The stories and the memories evoked illustrate the concept of cultural métissage, whereby the learning of traditional and Indigenous arts-based processes demonstrate transformations and intersecting spaces in language, culture and practice (Viera, 2014).

Storytelling is recognized as an Indigenous form of research as it is central to understanding Indigenous epistemologies (Lavallée, 2009; Wilson, 2008). According to Kovach (2009), stories serve to "elevate the research from an extractive exercise serving the fragmentation of knowledge to a holistic endeavor that situates research firmly within the context of relationship" (p. 99). This study used symbol-based learning and story-circle focus groups which privileged oral traditions and were premised on the reciprocal relationship between the teller and listener (Kovach, 2009; Lavallée, 2009). The familiarity of such approaches to those who have grown up in Indigenous communities contributed to local and personal knowledgesharing while exposing important socio-political realities.

The practice of using story-circle focus groups in Saskatchewan involved participants sitting in a circle with items symbolic of their weaving or beading experiences placed on a cloth in the centre. Similar to a talking circle, the study participants responded one by one to a study question by taking turns speaking in a clockwise direction. Often, one of the speakers would point or pick up an item from the centre of the circle and use it to embellish or tell their story. For some participants, the items had spiritual significance and meanings that reflect Indigenous cultural practices and ways of knowing (Lavallée, 2009). In this way, the arts themselves play an integral role in sustaining the memories, teachings and material cultural practices implied by their design and creation (Tehrani \& Riede, 2008). As one Saskatchewan beader said, 'It's not just a sense of living, it's a part of making, it's a piece of art. It expresses how you feel, it expresses what you are doing at the time." Trust, equity, and reciprocity were advocated through adherence to the principle of a talking circle, respect for the symbols within the circle, and a decentered position for the researcher.

Engaged Scholar Journal: Community-Engaged Research, Teaching and Learning 


\section{Study Participants and the Gatherings in Saskatchewan and Chile}

Saskatchewan. In keeping with Indigenous methodologies, Indigenous-centered research sites were sought for the story-circle focus groups. The first story-circle focus group, which had double the number of participants expected, involved 14 beaders, aged 24 to 95 years, who met at Wanuskewin Heritage Park, an Indigenous World Heritage site. The site was chosen because of its significance to Indigenous people as a "gathering place" and "a global centre of excellence in fostering education and respect for the land based on expressions of Indigenous culture" (Wanuskewin Heritage Park, 2016). Most of the participants were originally from northern communities in Saskatchewan. The session was opened by an elder and then participant consent forms and the University of Regina behavioural ethics approval were described in simple English. Participants consented separately to both audio and visual recordings. Indigenous students who worked on the study also had the opportunity to participate and learn in the process. Translation was available at all times, and three participants chose to speak in Cree, interspersed with English. A second story-circle focus group was held at the White Buffalo Youth Lodge, a youth cultural centre in the core area of Saskatoon that is "dedicated to improve the quality of life and health for children, youth, young adults and their families in the inner city through integrated, holistic support services" (White Buffalo Youth Lodge, 2016). One study participant, who was reluctant to participate in the story-circle focus group, was interviewed separately.

The study participants were asked in advance to bring samples of their beading work so that it could be shared with others in the group. This contributed to the informal learning that the research offered as well as to the community-building and gathering of "tools" for the story-telling pedagogies (Archibald, 2008; Deniston-Trochta, 2003). Stó:lo scholar and storyteller, Jo-Ann Archibald (2008) describes storytelling as a form of pedagogy that puts Indigenous epistemologies and principles of "respect, reverence, responsibility, reciprocity, holism, interrelatedness, and synergy" (p. 2) at the core. Time was built in for eating together, sharing knowledge informally, and responding to the research questions. The informal sharing was considered part of both the research process and the relationship building.

Chile. In Chile, finding research sites involved working with the relational networks I already established in Chile during previous work alongside the Mapuche and working with a collaborator at the Universidad de la Frontera in Temuco. In total there were 23 study participants in Chile from four communities. In three of these communities, the study participants had always worked with sheep and wool; the other community, Tirúa, had a larger number of women weavers, but the local research collaborators pointed out that weaving was not traditionally done in that community. Weaving in Tirúa had been assimilated into the community though an outside group as a way to generate economic activity among the women. I point this out as it suggests weaving may have different meanings from location to location. This may also be an example of cultural métissage whereby the assimilation of the weaving activity for economic purposes demonstrates a transformation of Indigenous identity (Viera, 2014). The inclusion 
of weaving as part of that identity appears not to have encroached on traditional Indigenous identity, despite being adaptive to changes that can be interpreted as colonial in nature.

Most of the participants in these four communities were unfamiliar with the other communities. Initially, the research team met with individuals in each of the four communities involved in the research. Two-three women from each of the four communities came together at a museum in Temuco for a larger focus group after the research was done in their original communities. Time was also built in for the women to visit the museum and socialize. A translator for Mapudugún-Spanish was also present.

\section{Understanding the Stories: Examples}

The stories shared by the participants illustrated sensory as well as narrative richness and were highly significant to the study. Two of those stories, one from Saskatchewan and one from Chile, are shared here. To protect the identity of the study participants, pseudonyms are used in the stories, and in the quotes which follow later in the article. In all cases, the quotes from Chile have been translated from Spanish into English. Quotes in Cree from one participant in the Saskatchewan circle story focus group were also translated into English. The story from a Saskatchewan participant which follows was delivered in English.

\section{Patricia: A Cree Story from Saskatchewan}

Often the stories shared in the Saskatchewan story-circle focus group, and particularly those shared by elders and middle-aged women, started with a description of hunting moose or tanning hides. The following story was told by Patricia, a beader. It was edited for length.

As long as I can remember, I've seen beads. Like maybe I was 3 or 4 and I seen mikisak [beads] all around the house, all the time, because my kokum [granny] was a beader. Both my kookums were beaders. And my mom was a beader and she always had pabkekin [hide] all over the house because when she said [pointing with her lips to another beader] "When you smell hide, you know you're coming home," it brought memories back because I remember when I used to go in to my granny's house and I used to like that smell.

And all my uncles and my dad, they're all hunters and they trap in the winter so I've seen lots of beaver pelts, [inaudible], oh everything, when I was growing up. When I was growing up I seen a lot of that, but my kids never seen that because we were already in the "civilized era" [laughter]. I used to go to my Auntie Jean's and she used to love to make hides every day. She always had one in the [front], and another drying and another one ready to be smoked. Constantly. She always had one hide almost done and one getting started. And my cousins used to come, and say "Come visit me!" and I'd say "Oh why?" and they'd say, "My mom's gonna do a hide." [I'd think] oh, I know what this means [laughter].

Another participant stated: [time to] pull the hides! [group laughter]. 


\section{Patricia continued:}

So every time they asked me to go over I'd say “no!” because I knew I'd be matabikewin [scraping hides] or something. [laughter] My other kookum, she used to always make me pull hides, eh? And I could never stand straight! [laughter] She used to always tell me "try and stand ... pull away from me" and then she'd pull and I'd be right SHHHHH [pulling motion/slumping over - laughter] I could never beat her. I tried, but I was too small. I think she just liked laughing at me.

When my kokum [granny] was done her hide, she'd post it inside the house, and she'd start everything going again. Like what you said [pointing to Deborah] -- they were constantly multi-tasking, eh? They're cooking, they're making bannock and you know, you're just sitting there like "What do I do?" and they just throw you a pan of beads or something and say, "Here! Keep busy! [laughter] Make a necklace or do something." They'd say, "kitapam [Look at her], she's just going really fast and making her mukluks or whatever she was making." One day she'd be done a pair of mukluks or something, and I'd just look at it and think "how can I do that?" and watch her do that all day. She'd get tired of me, looking at her, and get me to move, to get tea or something, just to get me out of her hair. [laughter] Cause I used to be just right there! [laughter] Then she'd push me away. That's how I learned to bead at a very young age. My mom too, used to just to keep me out of her hair she'd give me some beads and tell me to think of something to make. I made two pair of mukluks, and I've made a vest and I've made about, I don't know, 3 or 4 pairs of gauntlets.

As the stories were told, memories of relationships and of working together were continually being presented. These were amplified further when study participants took an object from the pile of objects in the centre of the circle just to illustrate a point. Frequently, as in Patricia's story, the memories included examples of the work women did in the home along with experiences such as tanning hides. Noticeable in the stories shared in both Saskatchewan and Chile were the ways the women reminisced about their familial relationships and how these relationships were impacted by global changes. Angela's story, which follows, illustrates this.

\section{Angela: A Mapuche story from Chile}

Angela, an elder of Mapuche ancestry, sits at the head of her dining table with her two adult daughters at her sides. Her long, grey hair is pulled back into a braid. She speaks softly but directly to her daughters in Mapudugun. She invites the research team to sit with her. One of the daughters passes the traditional local drink, mate, around the table, and we all share the mate through the same straw, and eat some fresh, home-made baking. We introduce ourselves, and we start to talk.

Angela used to be a weaver until her eye sight started to deteriorate and then an arm

\footnotetext{
5 As reported in Hanson, Fox Griffith \& Bedogni (2015).
} 
injury permanently impeded her ability to weave. However, she still enjoys separating and spinning the wool, which her daughters then dye and weave. When asked about her identity, she describes herself as the owner of the house, a mother of eight children, all women (and some weavers), and a long-term widow. She talks with pride about how all her daughters are independent and how they learned to look after each other after their father, Angela's husband, passed on.

Angela learned how to weave from her mother when she was 22 or 23 years old. As a child, she watched her mother and other elder women before she started weaving herself. She says that women used to weave more back then because "they did not need as much money as they do nowadays." They used to make their own blankets, and other household items and clothing that now they can buy. She also remembers Mapuche women wearing the traditional handmade chamal, which they now use only on special occasions, as industrial clothing has become the standard.

She describes the lengthy process of weaving, from looking after the sheep from which they get the wool, to spinning the wool and setting the loom. She talks about how she and her daughters used to make and mix coloring dyes from natural roots and plants, to apply to the wool and textiles. She recounts with a nostalgic delight how her daughters learned about weaving and dying, by playfully participating in the different steps of the weaving process. She laughs in complicity with her daughters as they share some funny anecdotes about their everyday childhood games and sisterly competitions involving the spinning of the wool, the buso. She talked about how the designs she learned from her mother have changed. She proudly discussed her oldest daughters, Magdalena, who lives in Santiago, and weaves on demand using patterns and designs that customers ask for and which are different from the traditional ones. She stated that the designs once came to the weavers in dreams.

Angela explains that she taught her daughters to weave because a woman who knew how to weave earned respect from her community. Women who wove were considered knowledgeable, and the weaving was traded for other goods to feed the family. In a matter-of-fact way, she acknowledged that the global economy affected this lifestyle.

Throughout the conversation, Angela struggled to find the right words in Spanish, mixing her discussion with Mapudugun. She lamented how her grandchild, along with other Mapuche youth, are losing their language, Mapudugun, because of Spanish and now English, which are taught in the school system.

The stories gathered in the study demonstrated Indigenous knowledge and epistemologies as multi-faceted-contextual, embodied, historical, and spiritual. The stories also helped to explain some of the contextual knowledge and comparisons between research sites and communities. This is explained further in the next section.

\section{Dealing with Contextual Knowledge, Comparisons, and Generalizations}

The original intent of the research was to share the experiences of the participants at each research site with a broader audience by creating two case studies based upon the stories shared by the women in each community. However, significant overlaps in the experiences 
of the women in Chile and Saskatchewan were observed and inevitable comparisons and generalizations were drawn from the findings. For example, the communities and the women themselves valued the practices of beading and weaving and overtly spoke of these practices as part of their Indigenous identities. Greenwood and Levin (2008) discuss the challenges involved in abstracting results from context-centered knowledges,comparing, generalizing, and communicating them, notably to academics. There was an attempt in analyzing the data to uphold these valuable practices, but also to use caution, in particular recognizing observations that evidently run counter to the dominant findings. The examples that follow illustrate commonalities and contextual knowledge.

In both locations, textile and garment work was considered to be something a Cree/ Mapuche woman ought to know. The Mapuche women spoke with pride about weaving as the greatest heritage they have from their mothers or grandmothers and said it defines their sense of culture and pride.

I learned in the courses how to weave and how to draw and now I'm teaching to my daughter who is fifteen, and to other girls. For us, this is a way to pass on our culture and that it remains in the textiles. We teach them how to weave so that they keep our culture in the textiles even if they want to do something else when they grow up. (Maria, Tres Cerros Chile)

Weaving was perceived as a way in which Mapuche women could make money because women have control over the money they earn from weaving. Weavers in Tirua, for example, illustrated this in Chile and a couple of the northern Saskatchewan beaders spoke about beading as a way of making some money when no other means was available. For the most part, however, both beading and weaving were seen by the study participants as activities that were outside of the global marketplace and not part of the dominant economic narratives. For the women, trading beaded and woven items was considered a traditional form of sharing (bartar), which might also, inadvertently, be measured as a form of resistance or resilience to the external pressures of the marketplace. According to the literature, there is a common thread connecting beading and Indigenous art; it is living, adaptive, and resilient, and it remains rooted in tradition (Robertson \& Farrell Racette, 2009). Blady (1997), for instance, suggests:

The adaptability, perseverance and ingenuity of the Métis people is seen in the elaborate and delicate beadwork they produced...The floral beadwork of the Metis is not only refined and understated in its aesthetic characteristics, but also as a medium of cultural expression and unity (pp. 142-143).

According to Ohmagari and Berkes (1997), the transmission of Indigenous knowledges through observation and emulation was impaired by the movement of people from traditional lands, changes in traditional pedagogies, and changes in value systems. Their findings seem to parallel the experiences of the weavers and beaders in Chile and Saskatchewan. More 
recently, the increased valuing of Indigenous ways (named by participants in both locations), including environmental awareness, is perhaps offering new incentives for, or a re-valuation of, traditional arts and ways of living off the land.

Many study participants felt that urban migration and globalization ${ }^{6}$ have strongly impacted younger generations. They lamented that when children left the community to pursue formal education, intergenerational learning was disrupted. Furthermore, school curricula, especially in Chile, have ignored Indigenous knowledge. Many participants said children are now more concerned with technology and making money, and not returning to Mapuche communities. The participants had very mixed responses to the values associated with dominant global trends. In both locations, however, study participants noted that a renewal of Indigeneity and an interest in Indigenous lives from non-Indigenous communities, including less overt racism, have made it easier to continue textile work.

The stories shared by the weavers and beaders provide a sense of place and demonstrate pieces of cultural and social history that sustain meaning in a world troubled by chaos and trauma. While Indigenous women in Canada were highly esteemed for their central role in securing the health and well-being of their families and communities (Brant Castellano, 2009), imposed colonial policies that systematically denigrated these roles and identities (WesleyEsquimaux, 2009). The Cree women's stories, however, suggested that beading provides a sense of relief from daily pressures, as explained by one study participant:

We're survivors. And that's what it [beading] is, it's surviving. It's surviving what society's been trying to put away. You know, they've done everything they can to try to make First Nations disappear, but as long as we keep sewing, as soon as we keep beading, as long as we keep making moccasins, whether it's hides or whether it's something like - on our regalia or anything. It's surviving. It's making our kids proud of who they are (BH, FG1).

The Mapuche women in Chile also shared how weaving reduced stress and led to feelings of well-being:

$[\mathrm{T} t$ is a feeling of joy when you are working on a piece [of textile]. I love to work on the loom, that is what I like the most, I feel happy while I am working because I will make some money... I do something good and pretty and people like it. (B-DH, FG1, Tirua)

Although the research sites were both isolated Indigenous communities, the concept of CoPs opened a space to consider perspectives that were both local and global in nature. In this space, the local and global boundaries could be seen as blurred and yet, interconnected. In addition to lessons on how knowledge is transmitted between generations, the study provided

\footnotetext{
${ }^{6}$ Globalization refers to the global trade in goods and services that form the basis of world economic systems. Such systems are increasingly dominant and governed by capitalism and free enterprise values.
}

Engaged Scholar Journal: Community-Engaged Research, Teaching and Learning 
valuable lessons in the resilience of Indigenous communities when faced with discrimination, and their creative, perhaps unintentional, resistance to the demands of globalization.

Local livelihood development provides alternatives to the macro-development inherent in globalization by offering alternate sources of income for families and communities and by strengthening "women's confidence in their ability to learn and contribute to their communities" (Jongeward, 2001, p. 96). A deeper understanding of how the context of globalization created spaces for resistance, that is, how Indigenous peoples simultaneously resist liberalized trade through cultural practices that defy the marketplace and which connect culture, communities and identities was an important outcome of this study. A powerful example of this was shared by Deborah, a woman from Saskatchewan, who did beadwork on a deer-hide jacket she had purchased at a garage sale. The symbols on the jacket - the prairie lilies, the infinity symbol or joining of two peoples, and the turtle as an Indigenous symbol associated with the earthwere beaded by Deborah to represent the identity and culture of the owner who is Metis. The jacket was also borrowed and worn by the President of the Metis Nation of Saskatchewan when he appeared before the Canadian Nuclear Safety Commission, both as a symbol of pride and identity, but maybe a suggestion of resistance to the lack of empathy from the Canadian government towards Indigenous people living around abandoned uranium mines in Northern Saskatchewan.

The stories shared by the participants also displayed differences in the histories of producing textile goods and garments in Chile and Canada. While many of the items were made for family use, the women in both countries relayed stories from the past and in the present where the woven or beaded items were used for trade or barter rather than cash. Here are quotes from both sites which illustrate this point:

I used to look at my mom weaving. Then she would go the border to trade for yerba (mate), sugar, flour, and they traded, they (speaks in Mapudugin), she never did it for money. She traded, always; she traded her weaving items for other things not for money. (P1, FG Temuco)

She said when we were young, my mom used to make a bunch of these moccasins and that, she made baskets and gloves, so that's what she's- that's how they learned and that's how they lived. They'd make their living from selling or trading them for something to eat and all that.... (Cecile, FG1, Saskatoon)

Beading is a necessity to feed my family. Because some of us are on welfare, and being on welfare is not enough to feed yourself for the whole month. So you got to have another means of supply. (Dot, FG1, Saskatoon)

Another learning garnered from the study participants was that beading and weaving are primarily learned intergenerationally. The participants described how they learned their skills by observing a family member. Both beaders in Saskatchewan and weavers in Chile noted that child's play and observation were the most common ways they learned the textile practice. 
Participants also discussed how learning through observation taught them patience. Older Mapuche women frequently laughed as they acknowledged that if they made mistakes, they were hit. Here are a few examples:

[My mom] asked me to help her to spin, and that is how you learn, you weave little by little, and if you messed up, you got a hit in the hand. So you better learn [laughs] (P7, Tirúa III)

Oh, anyways, all my aunties taught me how to do all of this. My father's sisters. They taught me how to fish and how to hunt and how to make hides. How to do berries and how to do everything to make us so we could survive without anybody around other than ourselves. I could dry meat. I could dry fish. I didn't go to school until I was 14. (Beatrice, FG1, Saskatoon)

Women noted that while beading or weaving, they were occasionally supervised, and frequently corrected, but that they had no formal training. They expressed, however, that this was changing and younger generations also talked about learning through university workshops and continuing education, not from their family members. Women in Chile also shared stories of learning to weave through cooperative organizations that were emerging to help with marketing their products. The cooperatives or community organizations were especially attractive for the older women who wanted to perfect and innovate their knowledge and techniques, as well as have the chance to speak their language and share with other women. As one participant in Chile explained, "[W]e built this cooperative, the women... Because the community is very small, and we didn't have a place to get together" (P9, FG Temuco). For the Saskatchewan women, the various aspects of hide preparation seemed to be primarily a skill of older generations. All the elders began their stories about the beading process with the hunt and the tanning of the hide, while the younger generations generally spoke only about the act of beading. One participant, Beatrice, described how the traditional, indigenous way of life she learned prior to being sent to an Indian Residential School, included learning all of the steps involved in harvesting and preserving food as well as making garments from the hides of the animals they hunted. She stated:

If you didn't know how to do this you weren't much of a woman. You had to learn to do it all, not just the fancy stuff. I had to learn to skin the moose, and do everything, hang it, take and put it on a stretcher, take everything off right from square one, put it in the water, smoking it and everything because we did it along with our food. You know, you dried the meat at the same time that you dried the hide. (B-DH, FG1)

The same tendency was found among the Mapuche weavers, wherein older women referred to the weaving process by first talking about the care of the animals from which they extracted the wool. One of the participants explained: "I learned when I was little, watching... my grandpa who wanted me to take care of the sheep... first I got the "palito" [stick], and that's 
how you learn." These comments seemed to imply Indigenous epistemological understandings of the land and the animals as interconnected to human lives. Nevertheless, while older women provided more 'holistic' descriptions of the weaving and beading processes, the younger participants were more specific and less likely to comment on the natural context of their textile work. In any case, questions about how the sources of the textile production are changing between generations remain open to further consideration.

Among the Saskatchewan women, there was a strong desire to share their knowledge about the textile production, especially within their families. In the community of the beaders, women spoke about how their sons, other male family members and the larger community were involved in the process, most notably in stretching the hides, but also in beading. The following exchange illustrated the involvement of some men.

They [the men] join in with the wives. They take out the flesh and the hair. The heavy part, hey. And the ladies do the smoking of the hide. I know of one guy that does [bead] he's a pow wow dancer, so his grandmother showed him how to bead and he was able to bead his own regalia (Ida, Interview).

Among the Mapuche participants from Chile, no stories of men weaving were shared. The participation of men was mostly described in relation to caring for the animals from which the wool was obtained. Although Mapuche boys and young men might occasionally help with setting up and other tasks, they are not expected to learn the skill of weaving, which is traditionally considered women's work. As one participant from Tirúa stated, "My son helps me sometimes, but he has his own job in agriculture."

\section{Reflections About the Findings}

The study provided lessons in working between and within Indigenous communities and identified possible challenges for adult educators interested in the ways younger generations interpret cultural knowledge. The results also illustrated ways in which epistemological understandings create different approaches to living, knowing, and being in the world. For example, the dominant view of the participants was that the textile work represented cultural identity and social relationships, particularly inter-familial.

Challenging the idea that study participants experienced the research equally is important in this kind of study and although initial generalizations about participant experience were made, the local collaborators and community coordinators provided reminders that context and local histories play a significant role in shaping experiences. For example, in Saskatchewan, interest in the practice of beading varied from spiritual to economical with many points in between. In Chile, some communities had developed a CoP due to available external funding and economic need. For instance, in Tirúa the weaving was supported by an NGO and although weaving was widely practiced there, it was not traditional to that area. Thus, the participants' stories were different, as were also the meanings associated with learning, teaching, and working with textiles in that area. 
Some research findings showed how textile work was integrated into the lives and wellbeing of the learners and their communities. Conversely, the implications for intergenerational learning when youth are taken out or leave their communities to attend school, whether it was Indian Residential Schools in Canada or secondary schools outside of the communities in Chile (and Canada), are worthy of additional research. Removing the youth interrupted the informal learning cycle associated with textile production and created ruptures in the kinds of values and meanings passed on to the younger generation. Explicit in the results obtained in this study was the role of intergenerational learning in the sharing of contextual and cultural knowledge, particularly language. The translation of traditional languages such as Cree and Mapudugún into English and Spanish was a challenge to researchers and participants alike, who recognized how easily the subtle, more nuanced meanings intended by the Elders were changed or lost. While the use of Indigenous languages was widely encouraged, for the most part, participants spoke in English in Saskatchewan or Spanish in Chile, occasionally adding words in their Indigenous languages. The efforts made to accurately translate Indigenous languages when spoken by the elders in the telling of their stories, often by participants from the younger generations, may also demonstrate the concept of cultural métissage.

In Saskatchewan, an unexpected outcome of this study was the increased involvement of community members in the practice of beading. For example, in one community, a few of the study participants decided to hold their own gathering of beaders. From this gathering they learned that there were beaders in their own family who had not shared their beading previously. Importantly, they acknowledged the value in sharing with family. A key component of the Indigenous research methodologies used in the study was working with participants to decide how the knowledge generated would be shared with the public. This resulted in an art exhibition and a publication. While this added to the complexity of the study, upon critical reflection, the researcher was awakened to how this ensured more equitable distribution of power in the research process.

\section{Sharing the Results}

The research mobilization phase of the project involved asking the study participants how they wanted to share the results of the research to a wider audience. In Saskatchewan, Canada, the study participants requested an exhibition; in Chile, they asked for a book about the study (Hanson, Griffith \& Bedogni, 2015). In Saskatchewan, several art and craft galleries were approached and an art gallery in northern Saskatchewan agreed to host the exhibition. Importantly, it demonstrated a commitment by the CoP to teach others. While the organization of the event alone was challenging, a second challenge was in relation to the lack of previous connections and relationships between the gallery and the beaders. Consequently, the participants' comfort levels in entering the gallery, even to put their items on display, was fraught with unexpected tensions and doubts from participants about whether their work was appropriate. One reluctant participant eventually showed up at my house with her items sorted into frames and she meticulously shared the story they told of intergenerational learning in her family. In addition to the items displayed in the show, a poster was developed for each beader,

Engaged Scholar Journal: Community-Engaged Research, Teaching and Learning 
which represented a bit of her history and included a quote about her work.

Challenges also arose while writing the book requested by the weavers in Chile. One significant challenge was representing the learning and understandings that emerged from the study in written form, albeit for an audience of participants from an oral culture. The research collaborators in Chile, while willing to distribute the book to the study participants, were unable to participate in the writing of the book as originally hoped. Consequently, writing the book requested by the weavers became the principle responsibility of the researcher along with two graduate co-authors. The bi-lingual book, titled Tejiendo Historias entre Géneraciones: Weaving Stories between Generations was published in paper and e-book formats. Copies of the book were distributed to all of the study participants in Chile by the researcher and community collaborators in Chile.

The local delays in knowledge mobilization also illustrate the complexities particular to working with marginalized populations in contrast to the demands of funding and academic schedules. They are, however, part of understanding a decolonizing methodology and of deconstructing how representational and political borders limit possibilities for fully understanding interconnections between people and places.

\section{Enter the Contact Zone: Concluding Thoughts}

Ten days prior to the opening of the art exhibition - Beading Between Generations - there was nothing to put on display. To get the items for the exhibition, I spent many hours driving to reserve communities, meeting people in parking lots, and spending time, via relational networks, to contact study participants by phone. The conundrum, however, opened up opportunities to attend feasts and develop new relationships in Indigenous communities as the beaders introduced me to their families and local band councils.

In addition to introducing the work of the Indigenous women to a wider audience-academic, community-based, collectors, artists and the public - the exhibit was a source of pride and, additionally, a way for women who previously had not entered the art world of galleries to make their presence known. The process, which could be described as "crossing borders" (Pratt, 1991) involved trying to connect the art world with Indigenous communitybased knowledge and connections between different Indigenous cultures that morphed with textile learning. Perhaps it illustrated Pratt's notion of contact zones which refers to the geographical and ethnographically conceived places and spaces where disparate cultures meet and try to engage.

Engaging in research that involved a non-Indigenous researcher building relationships and collaborations that value Indigenous people's lived experiences and epistemologies took personal commitment beyond the scope of traditional Western academic paradigms. This commitment involved crossing borders. Along with patience and a solid belief in the importance of the research to the lives of the women and communities involved, the research process included building relationships with communities, developing ethical and appropriate frameworks, and implementing Indigenous arts-based methodologies. The methodologies and methods provided important insights into how learning in the CoPs was structured and 
passed on to subsequent generations. The engagements with the CoPs built relationships with a wider public including the art gallery, the academic collaborators, Indigenous places such as Wanuskewin, the art curator, and so on. When the women in one community formed their own beading group, they demonstrated how such learning could be enhanced or sustained within the community itself. This kind of intergenerational learning and knowledge transfer seems reconciliatory, perhaps an area of additional inquiry. Meeting the dynamics of engagement and maintaining the rigour of the research was possible because of the relational networks and also by flexibility throughout the process.

Flexibility helped to alleviate some of the resistance of participants to the study and the researcher, as did community coordinators who deferred to local experience and helped to bridge the border worlds at each research site. For example, signing the ethical consent forms was viewed with suspicion by two Chilean participants, but when local community coordinators first explained the consent form in simple Spanish, it was more easily accepted. On another occasion, an elder questioned why children under eighteen could not participate in the study noting that this was contrary to Indigenous traditional ways of living and learning together. While the researcher explained that this was due to university guidelines and ethical considerations, it was the community coordinator's explanation that was most easily accepted. This may be due to her position within the community and personal relationship with the study participants.

The experience of the research mobilization offered flexible ways of sharing and understanding knowledge, some of which interrupt traditional power dynamics and challenge Western, colonial values and institutional norms. Most importantly, the study provided entries for new ways of imagining intergenerational learning and collaborative research based on mutuality, well-being, decolonizing practices, and holistic understandings.

\section{Acknowledgements}

The author, Cindy Hanson, gratefully acknowledges the Social Sciences and Humanities Research Council (SSHRC) for funding this study. She also acknowledges the participation of collaborators at the Universidad de la Frontera (UFRO) in Chile. 


\section{About the Authors}

Heather Fox Griffith is a PhD Candidate. Her research interests are in critical victimology. Heather's range of background experiences outside of her present academic interests are related to counseling and narrative therapy, conflict resolution and mediation, healing and resiliency. She is a skilled textile artist.

Cindy Hanson, PhD (corresponding author) was the researcher in this SSHRC funded study. She is an associate professor at the University of Regina and Director of the Adult Education Unit. This research builds on her life history with and in Indigenous communities in Canada and Chile, including work in Indigenous education for secondary and post-secondary institutions, coordination of elder's programs, and everyday activism. Email: Cindy.Hanson@uregina.ca

\section{References}

Allen, C. (1999). Blood (and) memory. American Literature. 71(1), 93-116.

Archibald, J. (2008) Indigenous storywork: Educating the heart, mind, body, and spirit. Vancouver: UBC Press.

Battiste, M. \& Henderson, S. Y. (2000). Protecting Indigenous knowledge and heritage: A global challenge. Saskatoon: Purich Publishing.

Blady, S. (1995) The flower beadwork people: Factors contributing to the emergence of distinctive Metis cultural artistic style at Red River from 1844 to 1869 (Masters thesis). University of Victoria, British Columbia.

Brant Castellano, M. (2009). Heart of the nations: Women's contribution to community healing. In M. Dion Stout, E. Guimond, \& G. Guthrie Valaskakis (Eds.), Restoring the balance: First Nations women, community, and culture (pp. 203-235). Winnipeg: University of Manitoba Press.

Bourdieu, P. (1991). On symbolic power, language and symbolic power. Cambridge, UK: Polity.

Chilisa, B. (2012). Indigenous research methodologies. Los Angeles, CA: Sage Pub.

dé Ishtar, Z. (2005). Striving for a common language: A White feminist parallel to Indigenous ways of knowing and researching. Women's Studies International Forum, 28, 357- 368.

Deniston-Trochta, G. M. (2003). The meaning of storytelling as pedagogy. Visual Arts Research, 29, (57), 103-108.

Denzin, N. K., Lincoln, Y. S., \& Smith, L. T. (Eds.). (2008). Handbook of critical and Indigenous methodologies. Thousand Oaks, CA: Sage Publications.

Ermine, W. J. (2000). The ethics of research involving Indigenous peoples (Masters thesis). University of Saskatchewan, Saskatchewan.

Fenwick, T. (2003). Reclaiming and re-embodying experiential learning through complexity science. Studies in the Education of Adults, 35(2), 123-141.

Greenwood, D.J. and Levin, M. (2008). Reform of the social sciences and of universities through action research. In N.K. Denzin, N.K, and Y.S. Lincoln (Eds.). The Landscape of qualitative research (pp. 57-86). Thousand Oaks: Sage Publications. 
Haig-Brown, C. (2008). Taking Indigenous thought seriously: A rant on globalization with some cautionary notes. Journal of the Canadian Association for Curriculum Studies, 6(2), 8-24.

Hanson, C., Fox Griffith, H., Bedogni, R. (2015). Tejiendo historias entre géneraciones: Weaving stories between generations. Regina: Lifewrite Publishing.

Henderson, J. Y. (2000). Ayukpachi: Empowering Aboriginal thought. In M. Battiste, Reclaiming Indigenous voice and vision (pp. 248-278). Vancouver: UBC.

Jongeward, C. (2001) Alternative entrepreneurship in Thailand: Weavers and the Northeastern handicraft and women's development network. Convergence, 34(1), 83-96.

Kajner, T. (2015). Construction and mediation of the "other" in community-engaged scholarship: The importance of not-knowing. Engaged Scholar Journal: Communtiy-engaged Research, Teaching, and Learning. 1(1), 15-32.

Kovatch, M. (2009). Indigenous methodologies: Characteristics, conversations, and contexts. Toronto: University of Toronto Press.

Lavallée, L. (2009). Practical application of an Indigenous research framework and two qualitative Indigenous research methods: Sharing circles and Anishnaabe symbol-based reflection. International Journal of Qualitative Methods, 8(1), 21-40.

Lave, J. and Wenger, E. (1991). Situated learning: Legitimate peripheral participation. New York: Cambridge: University Press.

Markowitz, S. J. (1994). The distinction between art and craft. The Journal of Aesthetic Education. 28(1) $55-70$

Merriam, S. B., Cafferella, R. S., \& Baumgartner, L. M. (2007). Learning environments and learning concepts, In Learning in adulthood: A comprehensive guide (pp. 27-52). San Francisco: John-Wiley and Sons.

McNiff, S. (2004). Research in new keys: An introduction to the ideas and methods of arts-based research. Journal of Pedagogy Pluralism and Practice, 3(1).

Ohmagari, K. \& Berkes, F. (1997). Transmission of Indigenous knowledge and bush skills among the Western James Bay Cree women of the Subarctic Canada. Human Ecology, 25(2), 197-222.

Peters, M. A., Burbles, N. C. (2004) Poststructuralism and educational research, Lanham: Rowman \& Littlefield Publishers.

Pratt, M. L. (1991). Arts of the contact zone. Profession 91. (pp. 33-40). New York: MLA.

Robertson, C. \& Farrell Racette, S. (2009). Clearing a path: New ways of seeing traditional Indigenous art. Regina: University of Regina Press.

Sinclair, M. (2014). Education: Cause \& solution. The Manitoba Teacher, 93(3), 7-10

Smith, L. T. (1999). Decolonizing methodologies: Research and Indigenous peoples. Dunedin, NZ: University of Otago Press.

Smith, L. T. (2012). Decolonizing methodologies: Research and Indigenous peoples. (2nd Ed). London: Zed Books.

Snyder, W. \& Wenger, E. (2004). Our world as a learning system: A communities of practice approach. In Social learning systems and communities of practice. (pp. 107-124). London: Springer.

Tehrani, J. \& Riede, F. (2008). Towards an archaeology of pedagogy: Learning, teaching and the generation of material culture traditions. World Archaeology, 40(3), 316-331, DOI: $10.1080 / 00438240802261267$

Vierea, R. (2014). Life stories, cultural métissage, and personal identities (pp. 1-12). SAGE Open, $4(1)$

Engaged Scholar Journal: Community-Engaged Research, Teaching and Learning 
Wanuskewin Heritage Park (2016). Our story - Mission vision and values. Retrieved from https:// wanuskewin.com/our-story/mission-values

Wenger, E. (2006). Communities of practice: A brief introduction. In Introduction to Communities of practice: A brief overview of the concept and its uses: Retrieved from www.ewenger.com/ theory/

Wesley-Esquimaux, C. (2009). Trauma to resilience: Notes on decolonization. In M. Dion Stout, E. Guimond, \& G. Guthrie Valaskakis (Eds.), Restoring the balance: First Nations women, community, and culture (pp. 13-34). Winnipeg: University of Manitoba Press.

White Buffalo Youth Lodge, (2016). Description of program. Retrieved from http://www.sktc.sk.ca/ programs-services/family-community-services/community-supports/white-buffalo-youthlodge/

Wilson, S. (2008). Research is ceremony: Indigenous research methods. Black Point, Nova Scotia: Fernwood Publishing. 